\title{
Students with Autism Spectrum Disorders and Their Neuro-typical Peers - Differences and Influences of Loneliness, Stress and Self-efficacy on Life Satisfaction
}

\author{
Carmen Feldhaus", Ute Koglin, Jens Devermann, Hanna Logemann, Alfred Lorenz \\ Department of Special Needs Education \& Rehabilitation, University of Oldenburg, Germany
}

Copyright (C) 2015 by authors, all rights reserved. Authors agree that this article remains permanently open access under the terms of the Creative Commons Attribution License 4.0 International License.

\begin{abstract}
The purpose of this study was to explore the interrelationships among the effects of loneliness, stress and self-efficacy on the life satisfaction of people with autism spectrum disorders (ASD) and their neuro-typically developed peers. The participants $(\mathrm{N}=104)$, all male, were between 15 and 27 years of age. Half of them were diagnosed having ASD the other half were neuro-typical. They completed several self-reported measurements. We found significant differences between the two groups in reported loneliness, life satisfaction and self-efficacy. The conclusions point towards the need for broader studies of self-efficacy and life satisfaction of people with ASD and a reconsidering of the universality of developmental tasks.
\end{abstract}

Keywords Autism Spectrum Disorders, Life Satisfaction, Self-efficacy, Loneliness, Stress, Neuro-typical Peers

\section{Introduction}

By reaching adolescence, young people have to face several challenges due to physical and psychological changes in themselves. Specific developmental tasks at this age are: developing autonomy from parental control; shaping of same-gender and opposite-gender relationships; and establishing one's own identity. As empirical studies demonstrate, adolescents who successfully manage these developmental tasks show a higher level of life satisfaction [1]. With regards to ASD-diagnosed youth, these developmental tasks can be seen as a major challenge. Youth with ASD experience difficulties in social functioning. They show manners that are inappropriate concerning non-verbal behavior and are often incapable of making contact with peers or older people. Due to DSM-5 core criteria of ASD are "persistent deficits in social communication and social interaction across multiple contexts, as manifested by the following: [...] 1. deficits in social-emotional reciprocity $[\ldots], 2$. deficits in nonverbal communicative behaviors used for social interaction $[\ldots], 3$. deficits in developing, maintaining, and understanding relationships." [2, 3, 4, p. $27 \mathrm{f}$. Difficulties with managing developmental tasks may reduce the life satisfaction of young adults with ASD. The aim of this study is to analyze the differences between the life satisfaction of neuro-typical youth and people with ASD in adolescence and young adulthood.

From a theoretical perspective, there are diverse explanations of life satisfaction. On the one hand, life satisfaction can be described as a personality trait which features a heavily genetic basis [5]. On the other hand, there are theories which emphasize the influence of life events on life satisfaction. One such theory is Hobfoll's [6] "Conservation of Resources Theory" (COR-Theory). He points out that personality traits and life events affect life satisfaction. The theory can be seen as a general approach to describing well-being/ life satisfaction and stress. Resources are one main aspect of this model. Hobfoll [6] defines resources as "those objects, personal characteristics, conditions, or energies that are valued in their own right, or that are valued because they act as conduits to the achievement or protection of valued resources"[6, p. 339 cited in $7 ; 8]$. Thus, resources can be tangible, or not tangible, like self-efficacy. They enable a person to satisfy physical and psychological needs and they therefore help determine personal well-being. In this study we will focus on resources such as self-efficacy and loneliness of adolescents and young adults with and without ASD with regards to life satisfaction. That means we go in line with Hobfoll [6] and set loneliness, stress and self-efficacy as resources. Life satisfaction can be defined as "the question of what leads people to evaluate their lives in positive terms" [9, p. 13].

\section{Self-efficacy}

One resource that plays a part in contributing to life satisfaction is self-efficacy. Studies show, that self-efficacy can significantly predict the life satisfaction of young adults [10-12]. Self-efficacy can be seen as a cognitive, social, emotional and behavioral composition of skills. These must be coordinated and arranged according to the immediate situation in order to use its generative potential. There is a discrepancy between having the aforementioned sub-skills and being able to use them in specific social interactions, however. Some people just cannot integrate them properly and often fail, although they actually know what to do. 
"Perceived self-efficacy is concerned not with the number of skills you have, but with what you believe you can do with what you have under a variety of circumstances" [13, p. 37]. Perceived efficacy is about how you think you perform, not about how you actually perform. Summarizing, "perceived self-efficacy is an important contributor to performance, whatever the underlying skills might be" [13, p. 37].

There is little empirical data referring to people with ASD and self-efficacy. Nevertheless, there is some evidence which indicates that, on one hand, they develop at least some form of self-awareness [14, p. 250]. On the other hand, there are findings that children with ASD are able to accurately reflect on their negative thoughts such as anxiety and depression [15, p. 975]. And first results in a study on the Quality of Life of people with ASD show that they rate the importance of "making my own decisions" very high (up to 9 and 10 on a ten-point Scale) [16]. For Bandura [13] "belief of personal efficacy constitutes the key factor of human agency. If people believe they have no power to produce results, they will not attempt to make things happen" (p. 3). In line with the results of Schmitz-Feldhaus [16] we will prove the relation between self-efficacy and life satisfaction.

\section{Loneliness}

According to Hobfoll [6], loneliness is an additional factor to influence life satisfaction. People who feel lonely often have problems entering into a relationship, trusting others and experiencing intimacy. It is difficult for them to get in contact with others, to talk to others about their emotions, and to feel comfortable in social interactions generally. Lonely people are rather introverted and have a low level of emotional stability and open-mindedness. They tend to give pessimistic explanations of their environments. They see most of the doings around them as beyond their control and interpret the actions/ motives/ behavior of others rather negatively as well. There are additional personality traits which could be considered in conjunction with loneliness, but those do not become visible directly. [17, p. 640f] Loneliness hits the highest level in the late teenager years/ early twenties. Coping with it is one of the important developmental tasks in adolescence. The increased number of people who feel lonely in that age group is reasonable. At that age they have to establish several new amicable relationships while undergoing job training and/ or studying. Later on they have to find their way in the world of employment. Additionally, some young adults might expect more from their intimate ties than grown-ups. Those may have learned to compromise. The older a person gets, the easier he/ she can accept and cope with loneliness [18, p. 632].

For people within the autism spectrum, loneliness is a severe problem. They have the ,desire to have friends without knowing how to make and keep them. This social conflict can result in loneliness and sometimes leads to the person using unusual ways to attract friends and, when entering adulthood, significant others" $[19$, p. 73$]$. One might argue that youth with autism spectrum disorders could have difficulties understanding the concept of loneliness because of their disability. But ,children with autism revealed as complex an understanding as did typically developing children of the more emotional aspect of loneliness" " $[20, p$. 500]. Another aspect to be considered is the correlation between loneliness and anxiety. White and Roberson-Nay [21, p. 1011] found that a reported experience of loneliness goes along with an increased level of anxiety. This connection is understandable, since apprehension could influence a child's level of seeking interactions with peers. So, up to a point, like their neuro-typical peers, people with ASD crave friendships. However, they must face the problem that they have much more trouble initiating and managing relationships. [3, p. 81]

\section{Stress}

The ability to cope with life events may help prevent some kinds of stress. Stress can "be treated as an organizing concept for understanding a wide range of phenomena of great importance in human $[\ldots]$ adaptation. Stress, then, is not a variable, but a rubric consisting of many variables and processes" [22, p. 11f cited in 23]. It is seen as an aspect of the association between people and their surroundings. That means that there are always two parts to be considered. The one is the individual and his or her personality and the other is the set of events that take place in his environment. Summarizing this, a person might experience psychological stress when his resources are taxed or when his well-being is at risk. Whether a given person sees a specific situation as stressful or not is associated with his or her cognitive appraisal of it [22, p. 21].

Considering stress with reference to people with ASD, it is known that any change in their lives, be it an alteration in the daily routine or a new employer, could result in major onset of anxiety or stress [24, p. 333]. In addition, it could be assumed, that in every job-related situation, a person with ASD faces stress, because every activity is conducted in an ASD-hostile environment. Only if the determining factors are alternated, the level of stress might be reduced [25, p. 64]. Attwood [3] points out those students with ASD have to learn according to the curriculum, just like their classmates. But for them school means a lot more stress, because they need to use their wits as well to conform to the social rules of the schoolyard [3, p. 298].

In this paper the authors position the Conservation of Resources Theory as the linking concept of the three statistically relevant aspects: life satisfaction, loneliness, self-efficacy and stress. All of them are seen as personal characteristics or conditions and thus a resource. As mentioned before, young adults have to accomplish specific developmental tasks. For young adults this results in an increase of perceived pressure, which might cause low life satisfaction. Well-marked self-efficacy can help to cope with the developmental tasks. Thus we will assume a positive association particular between self-efficacy and life satisfaction regardless of an ASD diagnosis. Loneliness can be outlined as a missing resource and we estimate that increased loneliness will occur together with lower life satisfaction. An increased level of stress, however, should also be accompanied by lower life satisfaction. The next step is to check whether the association between the variables in 
people with and without ASD is similar or if they differ. The working assumption is that it is different in people with ASD, for example because they understand loneliness differently than neuro-typical people. [20]

The purpose of the present study was to:

1. Analyze the hours spend alone, comparing both groups (youth with ASD and NTs).

2. Calculate the correlation between the variables (hours spend alone; enjoy being alone, stress, loneliness, life satisfaction and self-efficacy).

3. Calculate the descriptive statistics for stress, loneliness, life satisfaction and self-efficacy and analyze the difference between the two groups (youth with ASD and their neuro-typical peers).

4. Examine the extent to which ASD moderates the relationship between the resources (loneliness, stress, self-efficacy) and life satisfaction.

\section{Methods}

\section{Participants}

In this study $\mathrm{N}=104$ young male persons $15-27$ years of age were interviewed. Of these, $n=43$ youth had the official diagnosis ASD following the ICD-10-GM-2013 F84.5 criteria, while $n=61$ were neuro-typical. The young males with ASD were recruited via Autism-Therapy-Centers. First, the institutions were contacted and the project was presented. Second, the staff asked potential attendees to participate in the study. The survey was conducted via the online software LimeSurvey ${ }^{\circledR}$. A homepage with information referring to the project was produced produced for the survey. The control group consisted of an ad-hoc sample of young male students from collaborating schools and youth centers.

\section{Materials}

The degree of loneliness was assessed using a German version of the UCLA Loneliness Scale [26]. The scale consists of 20 items ( 10 positive and 10 negative) describing subjective feelings of loneliness, none of which refer specifically to loneliness (e.g., "How often do you feel part of a group of friends?", and "How often do you feel that you lack companionship?" The items are rated on a 5-point scale according to the rate of frequency, ranging from "not at all" (1) to always (5). Higher scores reflect lower loneliness. The internal consistency of the sample at hand is $\alpha=.94$ for the whole sample (neuro-typical $\alpha=.95$ and people with ASD $\alpha$ $=.90)$.

To provide an estimate of the prevalence of loneliness, the self-labeling items "How many hours a day do you spend alone, on average?" and "How much do you like being alone for these hours?" were used to measure to what degree the students considered themselves to be lonely. Respondents used a six-point scale from $1=$ "not at all" to $6=$ "very much".

To gather data about stress, the screening scale of the Trier Inventory for the Assessment of Chronic stress (TICS) [27] was applied. The scale consists of twelve items with a five-point rating scale from "never" to "very much". The participants were asked to assess how often a specific situation was experienced (e.g. "Times where I have worried a lot and could not stop"). A sum score was issued to evaluate the results. The internal consistency of the sample at hand is $\alpha=.92$ for the whole sample (neuro-typical $\alpha=.93$ and people with ASD $\alpha=.90$ ).

Self-efficacy was measured by three items. For each item the participants rated their self-efficacy beliefs on a five-point scale from $1=$ "not at all" to $5=$ "very much" (e.g. "Most problem I can solve by myself, very good"). The internal consistency of the sample at hand is $\alpha=.84$ for the whole sample (neuro-typical $\alpha=.87$ and people with ASD $\alpha$ $=.81)$.

Life satisfaction is seen as the individual appraisal of one's own current living conditions [28]. To assess life satisfaction the participants were asked to respond to five items, which covered different domains of life such as: school/ employment; finances; family; friendships and leisure time activities ("how satisfied are you with..."). The items were rated on a five-point scale from very unhappy (1) to very happy (5). To evaluate the results, a sum score was issued. This scale yielded Cronbach's a coefficients of $\alpha$ $=.94$ for the whole sample (neuro-typical $\alpha=.95$ and people with ASD $\alpha=.90$ ).

\section{Procedure}

Pearson's correlations were computed to examine the bivariate relationships between life satisfaction and loneliness, stress, self-efficacy and hours spent alone. To verify which variables predict life satisfaction, hierarchic regressions were used. Interaction terms were inserted to check whether the correlation between the variables regarding young people with ASD differs from those referring to people without ASD. Prior to the analysis, the dependent variables were mean cantered, and the interaction terms were computed using cantered variables. By way of Kolmogorov-Smirnov-Test the unstandardized residuals were tested for a normal distribution. The assumption of a normal distribution could be expected $(0,08 ; \mathrm{df}=104 \mathrm{p}=.16)$.

\section{Results}

The young men mentioned that they spent $6.73(\mathrm{SD}=4.82)$ hours a day alone, on average. Those with ASD three hours longer $(\mathrm{M}=8.81, \mathrm{SD}=5.71)$ than the neuro-typical male $(\mathrm{M}$ $=5.24, \mathrm{SD}=3,42 ; \mathrm{t}=-3,65, \mathrm{p}=.001)$. Both groups tended to enjoy spending that time alone, though, and there are no significant differences between them $(\mathrm{ASD} \mathrm{M}=4.44, \mathrm{SD}=$ 1.72; neuro-typical $\mathrm{M}=4.21, \mathrm{SD}=1.36 ; \mathrm{t}=0.89, \mathrm{p}=.37)$.

Table 1 shows the correlation between the variables. The number of hours spent alone was significantly correlated with stress and loneliness as well as with lesser self-efficacy. People who enjoyed being alone for those hours, had a higher self-efficacy. Further, relatively high correlations within the sample were found between life satisfaction, stress and loneliness, which range between .47 and .60 .

We checked whether there were differences between the groups regarding the observed variables (s. Tab 1). It can be noted that there are significant differences between the 
groups concerning loneliness, life satisfaction and self-efficacy. The young people with ASD showed higher marks for loneliness and lower ones for life satisfaction and self-efficacy. However, both groups reported a similar level of stress in the preceding three months. The differences show a high effect of $\mathrm{d}=.93$, which means that the mean difference almost corresponds to a standard deviation. For life satisfaction, the mark of $\mathrm{d}=.43$ and for self-efficacy $\mathrm{d}$ $=.59$ was calculated.
To examine the extent to which ASD moderates the relationship between loneliness, stress and self-efficacy, hierarchical linear regression analyses were conducted with life satisfaction as the outcome. In a first step, the diagnosis ASD and the predictors self-efficacy, stress and loneliness were examined. In this model $\left(\mathrm{R}=.67 ; \mathrm{R}^{2}=.45, \mathrm{~F}(\mathrm{df}=4,99)=\right.$ $19,93 \mathrm{p}<.001)$ the variable ASD was not a significant predictor for life satisfaction $(\beta=.01, t=0.01)(\mathrm{s}$. Tab. 3$)$.

Table 1. Inter-correlation of the variables

\begin{tabular}{|c|c|c|c|c|c|c|}
\hline Scale & $\begin{array}{c}\text { Quantity of } \\
\text { hours spent } \\
\text { alone }\end{array}$ & $\begin{array}{l}\text { enjoy being } \\
\text { alone }\end{array}$ & Stress & Loneliness $^{\mathrm{a}}$ & Life Satisfaction & Self-Efficacy \\
\hline $\begin{array}{l}\text { Quantity of hours } \\
\text { spent alone }\end{array}$ & - & -.11 & $.26^{* *}$ & $-.56^{* * *}$ & -.16 & $-.32 * * *$ \\
\hline enjoy being alone & & - & -.09 & .14 & $.18^{+}$ & $.21^{*}$ \\
\hline Stress & & & & $.51 * * *$ & $.52 * * *$ & $.47 * * *$ \\
\hline Loneliness & & & & - & $.60 * * *$ & $.52 * * *$ \\
\hline Life Satisfaction & & & & - & - & $.50 * * *$ \\
\hline
\end{tabular}

${ }^{+} \mathrm{p}<.10, * \mathrm{p}<.05,{ }^{* *} \mathrm{p}<.01,{ }^{* * *} \mathrm{p}<.001{ }^{\mathrm{a}}$ Higher scores reflect lower Loneliness.

Table 2. Descriptive statistics for stress, loneliness, life satisfaction and self-efficacy

\begin{tabular}{|c|c|c|c|c|c|}
\hline \multirow[b]{2}{*}{ Scale } & \multicolumn{2}{|c|}{ Neuro-typical } & \multicolumn{2}{|c|}{ ASD } & \multirow{2}{*}{$\begin{array}{c}\text { Statistics } \\
\mathrm{t}\end{array}$} \\
\hline & M & SD & M & SD & \\
\hline Stress & 29.75 & 10.24 & 30.26 & 10.19 & 0.25 \\
\hline Loneliness $^{\mathrm{a}}$ & 80.49 & 12.12 & 68.77 & 13.08 & $4.70 * * *$ \\
\hline Life satisfaction & 18.69 & 3.00 & 17.16 & 4.06 & $2.10^{*}$ \\
\hline Self-efficacy & 11.75 & 2.04 & 10.28 & 2.85 & $2.91 * *$ \\
\hline
\end{tabular}

$* \mathrm{p}<.05, * * \mathrm{p}<.01, * * * \mathrm{p}<.001 .{ }^{\mathrm{a}}$ Higher scores reflect lower Loneliness.

Table 3. Hierarchic regression for life satisfaction

\begin{tabular}{|c|c|c|c|}
\hline & Scale & $\beta$ & $\mathbf{t}$ \\
\hline \multicolumn{4}{|l|}{ Step 1} \\
\hline & ASD & .01 & 0,09 \\
\hline & Self-Efficacy & .19 & $2,03^{*}$ \\
\hline & Stress & -.24 & $-2,56^{*}$ \\
\hline & Loneliness $^{\mathrm{a}}$ & .38 & $3,69 * * *$ \\
\hline \multicolumn{4}{|l|}{ Step 2} \\
\hline & ASD x Self-Efficacy & .30 & $2,15^{*}$ \\
\hline & ASD x Stress & -.02 & $-0,19$ \\
\hline & ASD x Loneliness & -.03 & 0,22 \\
\hline
\end{tabular}

${ }^{*} \mathrm{p}<.05,{ }^{* * *} \mathrm{p}<.001 .{ }^{\mathrm{a}}$ Higher scores reflect lower Loneliness. 


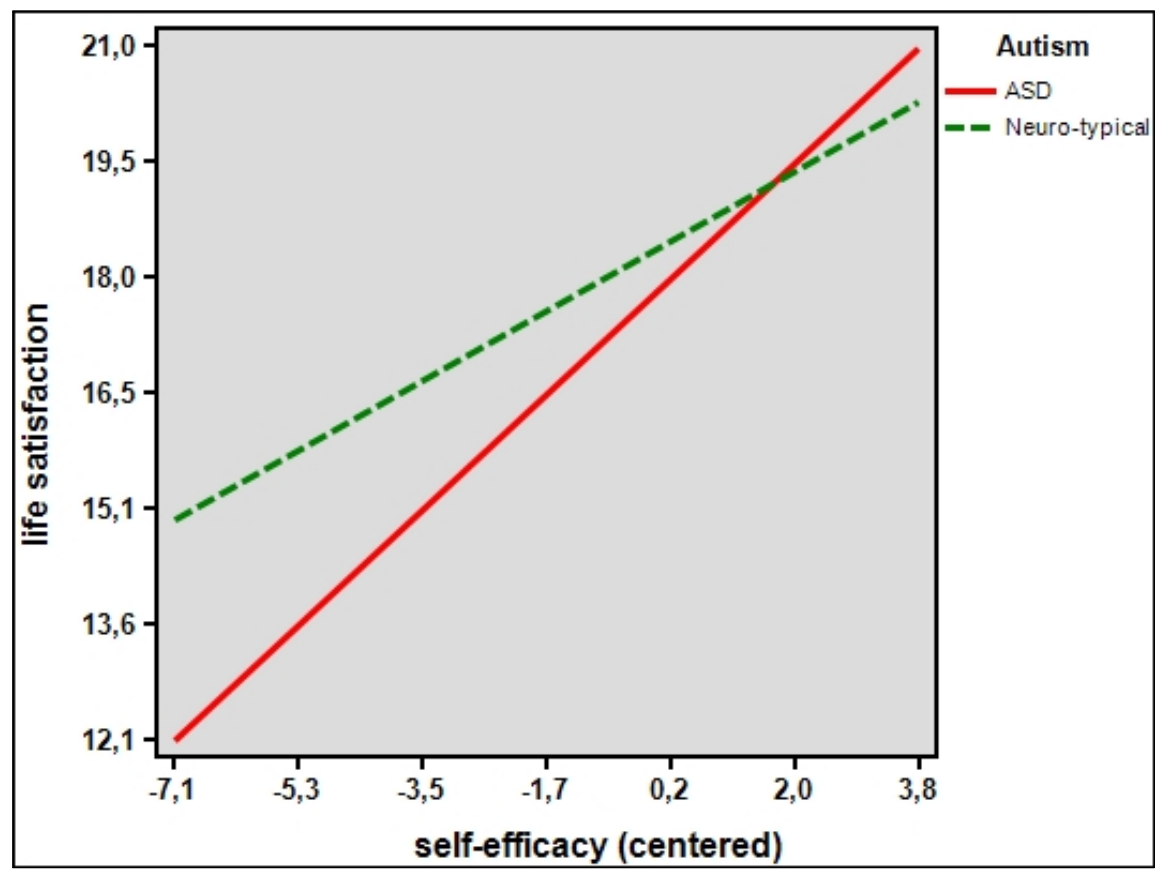

Figure 1. Interaction between ASD and Self-Efficacy on Life Satisfaction.

However, loneliness explains most of the variance, followed by stress and self-efficacy. In the second step, the interactions of the variables were included $(\mathrm{R}=.69 ; \mathrm{R} 2=.48$, $\left.\mathrm{R}_{\text {Change }}=0,4, \mathrm{~F}_{\text {Change }}=2,20 \mathrm{p}<.09\right)$. The interaction ASD $\mathrm{x}$ self-efficacy is significant. This hints at a difference between the connections of self-efficacy and life satisfaction in young males with and without ASD. Correlations make the interactions apparent. They show a $\mathrm{r}=.33$ for neuro-typical students and $\mathrm{a} r=.57$ for people with ASD. This means that the connection between self-efficacy and life satisfaction is considerably more pronounced for young males with ASD (s. Fig. 1).

\section{Discussion}

This study focused on examining the influence of self-efficacy, stress and loneliness in adolescents with and without the diagnosis of ASD on life satisfaction. With regards to Hobfoll's [6] Conservation of Resources Theory, self-efficacy, stress and loneliness can be seen as the resources that influence life satisfaction. On the basis of the actual sample, we found that these three aspects correlate with life satisfaction. However, there were differences between participants with ASD and their typically developing peers. Findings for people with ASD are: higher loneliness, lower self-efficacy and thus lower life satisfaction. Only in the case of stress could no differences between the two groups be identified. The results on loneliness are in line with the outcome of a study by Bauminger, Shulman, and Agam [20] where "high-functioning children with autism initiated and responded to peers at about half the rate of typical controls" [20, p. 502]. In addition to that, White and Robertson-Nay [21] reported that youth with ASD experience more social loneliness combined with an elevated level of anxiety. The study of Mazurek [29], examining the relationships between loneliness, friendship, and well-being in adults with ASD indicated that loneliness was associated with decreased life satisfaction.

Multivariate analysis for loneliness and stress attest to similar correlations with life satisfaction of people with ASD and their typical controls. The results do not show whether participants with ASD interpreted loneliness in different ways than neuro-typical persons did. However, the internal consistence of the scale $(\alpha=.90)$ is very good and lies just under the score of the people without ASD. Those with ASD reported that they were alone almost two hours longer per day and they obtained notably higher marks on average. In addition, the relationship between loneliness and life satisfaction is similar for both groups. According to the pattern the results show, we assume for this study that people with ASD and their neuro-typical peers had a comparable understanding of loneliness.

For self-efficacy, however, there are significantly different correlations for people with and without ASD. For individuals with ASD, the relationship between self-efficacy and life satisfaction is stronger than that for people without ASD. The belief in being able to achieve goals and desires independently is more strongly correlated with life satisfaction in individuals with ASD. There are as yet no publications on self-efficacy regarding life satisfaction for people with ASD, but for neuro-typically developed people some studies have been released. In their longitudinal design study Vecchio, Gerbino, Pastorelli, Del Bove and Caprara [30] interviewed 650 (317 male; 333 female) youths twice, five years apart. The participants were 13.5 years old on average and thus five years later 18.5. At time 1 the students were in middle school and measures of perceived academic, social and regulatory self-efficacy beliefs, academic achievement and social preference were taken. At the second survey point Diener's 5-item Life satisfaction scale was 
assessed and the four measures of self-efficacy were taken again. Hierarchical regression analysis of the results indicates that "for both genders, academic and social self-efficacy beliefs in early adolescence were better predictors of life satisfaction in late adolescence than early academic achievement and peer preference. Furthermore, change in academic and social self-efficacy beliefs significantly contributed to predict life satisfaction over the course of five years." [30, p. 1807] Following Hobfoll's conservation of resources theory, Feldman, Davidson and Margalit [31] studied personal resources (hope, self-efficacy and optimism) and achievement among college students. Their aim was to analyze the individual differences with regards to changes in the three personal resources. This was in relation to academic achievement over time and following a focused hope intervention workshop. They reported that on the one hand, academic achievement correlates with time and hope levels. On the other hand, they found that after the workshop, students' optimism and self-efficacy increased immediately.

\section{Recommendations}

In consideration of the aforementioned studies and our own results, we would like to emphasize the following:

(1) There is an urgent need for more studies concerning life satisfaction of people with ASD. But this should be done with an assessment that evaluates and considers the specific conditions of those persons and thus works with a measurement that is based on the affected persons' points of view. [32] This means that the instrument should be developed with their help as first described by Schmitz-Feldhaus [16].

(2) The effect of self-efficacy on life satisfaction as has been reported in short above is even stronger in people with ASD. We recommend that further studies on self-efficacy should be conducted in order to do justice on the affected people. This first and foremost because as Caprara, Alessandri and Barbaranelli [33] accentuate "interventions designed to nurture and strengthen a positive view of oneself, one's life and the future represent a major challenge for researchers, clinicians and health psychologists" [33, p. 328]. But interventions can only be successfully established if they are research-based.

(3) This leads to our final statement: The concept of developmental tasks first defined by Havighurst [34] might not be valid for people on the spectrum. We suggest that researchers and scientists need to write specific developmental tasks i.e. following Berk's [18] classification in the categories emotional development, temper development, relationship, language and so on, anew.

Limitations of the study include the small ad-hoc sample of $\mathrm{N}=104$ participants. A larger sample could give better information on the representativeness of the results regarding the wider population. In addition, our sample consisted of all male self-report participants. There are publications indicating the validity of using self-reports when studying people with ASD, but the scientific community is in disagreement $[35 ; 29]$. It would seem necessary to see whether there are gender-specific differences. The potential impact of response bias in terms of the characteristics of those who opt to participate in this study needs to be considered as well. We assume that an online-based measurement is more appropriate for people on the spectrum. But there is a lack of evidence and one needs to keep in mind that new media are not necessarily used by older people, diagnosis of ASD notwithstanding [16]. Another aspect is the variation in the scales used in this study. Above all, people with ASD might have problems when facing different sets of items.

The three recommendations might be a little farfetched in light of the limitations. Nevertheless we consider them important.

\section{REFERENCES}

[1] Schulenberg JE, Bryant AL, O'Malley P. Taking hold of some kind of life: How developmental tasks relate to trajectories of well-being during the transition to adulthood. In Development and Psychopathology. 2004; 16: 1119-1140.

[2] Kamp-Becker I, Bölte S. Autismus. München: UTB; 2011.

[3] Attwood T. Ein Leben mit dem Asperger Syndrom. Von Kindheit bis Erwachsensein - alles was weiterhilft. Stuttgart: Trias; 2012.

[4] American Psychiatric Association. Desk Reference to the Diagnostic Criteria From DSM-5. Arlington: APA; 2013.

[5] Lykken D, Tellegen A. Happiness is a stochastic phenomenon. In Psychological Science. 1996; 7(3): 186-189.

[6] Hobfoll SE. The influence of culture, community, and the nested self in the stress process: Advancing conservation of resources theory. In Applied Psychology. 2001; 50(3): $337-421$.

[7] Hobfoll SE. The ecology of stress. New York: Hemisphere Publishing Corporation; 1988.

[8] Diener E, Fujita F. Resources, personal strivings, and subjective well-being: A nomothetic and ideographic approach. In Journal of Personality and Social Psychology. 1995; 68: 926-935.

[9] Diener E. Subjective Well-Being. Psychological Bulletin, 95/3. American Psychological Association; 1984.

[10] Santos MCJ, et al. Establishing the relationship between general self-efficacy and subjective well-being among college students. In Asian journal of management sciences \& education. 2014; 3(1): 1-12.

[11] Cakar FS. The relationship between the self-efficacy and life satisfaction of young adults. In International Education Studies. 2012; 5(6): 123-130.

[12] Magaletta PR, Oliver JM. The hope construct, will, and ways: their relations with self-efficacy, optimism, and general well-being. In Journal of Clinical Psychology. 1999; 55: 539-551.

[13] Bandura A. Self-efficacy. The exercise of control. New York: W.H. Freeman and Company; 1997. 
[14] Bowler DM. Autism Spectrum Disorders; Psychological Theory and Research. Chichester: Wiley; 2007.

[15] Ozsivadjian A, Hibberd Ch, Hollocks MJ. Brief Report: The Use of Self-Report Measures in Young People with Autism Spectrum Disorder to Access Symptoms of Anxiety, Depression and Negative Thoughts. In Journal of Autism and Developmental Disorders. 2014; 44: 969-974.

[16] Schmitz-Feldhaus C. Nicht-traditionelle Studierende vs. traditionelle Studierende - Eine Onlinebefragung zum Sense of Coherence im Studium mit Fokus auf Menschen mit Beeinträchtigungen und Neue Medien. In Zawacki-Richter O, Kergel D, Kleinefeld N, Muckel P, Stöter J, Brinkmann K., editors. Teaching Trends 2014 - Offen für neue Wege: Digitale Medien in der Hochschule. Münster: Waxmann; 2014.

[17] Friedman HS, Schustack MW. Persönlichkeitspsychologie und Differentielle Psychologie. München: Pearson; 2004.

[18] Berk LE. Entwicklungspsychologie. München: Pearson; 2005.

[19] Shore SM, Rastelli LG. Understanding Autism for Dummies. Hoboken: Wiley; 2006.

[20] Bauminger N, Shulman C, Agam G. Peer interaction and loneliness in high-functioning children with autism. In Journal of Autism and Developmental Disorders. 2003; 33: 489-507.

[21] White SW, Roberson-Nay R. Anxiety, Social Deficits, and Loneliness in Youth with Autism Spectrum Disorders. In Journal of Autism and Developmental Disorders. 2009; 39: 1006-1013.

[22] Lazarus RS, Folkam S. Stress, Appraisal, and Coping. New York: Springer Publishing Company; 1984.

[23] Lazarus RS. Psychological Stress and the coping process. New York: McGraw-Hill; 1966.

[24] Sünkel U. Autismus-Spektrum-Störungen und die Arbeitswelt. In van Elst LT, editor. Das Asperger-Syndrom im Erwachsenenalter und andere hochfunktionale Autismus-Spektrum-Störungen. Berlin: MWV; 2013.
[25] Preißmann C. Asperger - Leben in zwei Welten. Stuttgart: Trias; 2012.

[26] Russel D. The measurement of loneliness. In Peplau L, Perlman D, editors. Loneliness: A sourcebook of current theory, research and therapy. New York: Wiley; 1982.

[27] Schulz P, Schlotz W, Becker P. TICS - Trierer Inventar zum chronischen Stress (Screening-Skala zum chronischen Stress (SSCS); Trierer Inventar zur Erfassung von chronischem Stress. Göttingen: Hogrefe; 2004.

[28] Diener E. Assessing Well-Being: The Collected Works of Ed Diener, Social Indicators Research Series 39. Heidelberg: Springer; 2009

[29] Mazurek MO. Loneliness, friendship, and well-being in adults with autism spectrum disorders. In Autism. 2014; 18(3): 223-232.

[30] Vecchio GM, Gerbino M, Pastorelli C, Del Bove G, Caprara GV. Multi-faceted self-efficacy beliefs as predictors of life satisfaction in late adolescence. In Personality and Individual Differences. 2007; 43: 1807-1818.

[31] Feldman DB, Davidson OB, Margalit M. Personal Resources, Hope, and Achievement among College Students: The Conservation of Resources Perspective. In Journal of Happiness Studies. 2014; 15(2): 339-355.

[32] Tavernor L, Barron E, Rodgers J, McConachie H. Finding out what matters: validity of quality of life measurement in young people with ASD. In Child: Care, health and development. 2012; 39(4): 592-601.

[33] Caprara GV, Alessandri G, Barbaranelli C. Optimal Functioning: Contribution of Self-Efficacy Beliefs to Positive Orientation. In Psychotherapy and Psychosomatics. 2010; 79: 328-330.

[34] Havighurst RJ. Developmental Tasks and Education. Chicago: University of Chicago Press; 1948.

[35] Berthoz S, Hill EL. The validity of using self-reports to assess emotion regulation abilities in adults with autism spectrum disorder. In European Psychiatry. 2004; 20: 291-298. 